\title{
Secondhand Tobacco Smoke Exposure in Indoor Workplaces in Viet Nam and Associated Factors: Findings from Two Rounds of Global Adult Tobacco Surveys (GATS) 2010 and 2015
}

\author{
Nguyen Tuan Lam ${ }^{1 *}$, Pham Thi Quynh Nga $^{1}$, Mina Kashiwabara ${ }^{2}$, Phan Thi \\ Hai $^{3}$, Doan Thi Thu Huyen ${ }^{3}$, Kim Bao Giang ${ }^{4}$, Hoang Van Minh ${ }^{5}$, Nguyen The \\ Quan $^{6}$, Luong Ngoc Khue ${ }^{3}$, Kidong Park ${ }^{1}$
}

\begin{abstract}
Objectives: This paper explores changes in the level of secondhand smoke (SHS) exposure at indoor workplaces between 2010 and 2015 in Viet Nam and the association between the exposure and various demographic factors, using data from Viet Nam's Global Adult Tobacco Surveys (GATS) 2010 and 2015. Methods: Data was pooled from the two GATS surveys and analysed using descriptive and Poisson regression analyses. Results: There was a highly statistically significant reduction in the level of SHS exposure at indoor workplaces from $55.9 \%$ to $42.6 \%$ ( $p<0.001)$ between 2010 and 2015. This equates to an additional 2.7 million people being protected from SHS exposure at indoor workplaces during the period. Of the demographic factors examined, being female was associated with a 30\% lower risk of SHS exposure, $\mathrm{p}<0.001$. An average worker in non-government category has $16.3 \%$ lower risk compared to self-employed workers. Compared with a workplace where smoking was completely banned, those who worked in a workplace with a partial indoor smoking ban had more than 2.9 times (aPR 2.94; $<<0.001$ ) higher risk of SHS exposure; workplaces with no smoking policy had nearly 4 times (aPR 3.97; $\mathrm{p}<0.001)$ higher risk; and workplaces that allowed smoking anywhere indoors had a 4.6 times (aPR 4.61; $\mathrm{p}<0.001)$ higher risk. Overall, for an average worker, the risk of exposure to SHS in reduced by $23.8 \%$ in 2015 compared to 2010. Apart from the above three factors, other factors not captured in the survey contributed to about $13.3 \%$ reduction in the SHS between 2010 and 2015. Conclusion: SHS exposure in indoor workplaces significantly reduced in Viet Nam between 2010 and 2015. The implementation of an internal smoking ban policy in the workplaces, reflecting the implementation of the national Tobacco Control law, plays the key role in protecting people from SHS exposure in the workplaces in Viet Nam.
\end{abstract}

Keywords: Secondhand smoke- Indoor workplace- GATS- Viet Nam

Asian Pac J Cancer Prev, 21, Progress of Tobacco Control in the Western Pacific Region Suppl, 33-38

\section{Introduction}

Secondhand tobacco smoke (SHS) is the combination of smoke emitted from the burning end of a cigarette or other tobacco products and smoke exhaled by the smoker. SHS contains thousands of known chemicals, at least 250 of which are toxic and more than 50 are carcinogenic (WHO, 2009). Involuntary or passive smoking occurs when an individual is exposed to SHS and involuntarily inhales the SHS carcinogens and toxic components (WHO, 2017). SHS has been found to increase an individual's risk of developing acute coronary heart disease, lung cancer, breast cancer, and nasal irritation, among other diseases (WHO, 2009). There is no safe level of exposure to SHS and everyone should be protected from such exposure (WHO, 2009). The workplace is one setting where a number of deaths associated with exposure to SHS are reported. The International Labour Organization, for example, estimates that globally, approximately $14 \%$, about 200,000, of all work-related deaths caused by diseases are linked to exposure to SHS in the workplace (ILO, 2005).

Implementation of smoke-free workplace not only protects the workers there but also facilitates tobacco cessation among smokers. Evidence has shown that smokers who work in smoke-free workplaces are twice as likely to quit smoking than those who work in places where smoking is permitted and they tend to reduce the amount of cigarettes they consume per day (Bauer et al., 2005).

Creating smoke-free environment in indoor workplaces is one component of the World Health Organization

${ }^{1}$ World Health Organization, Country Office for Viet Nam, Hanoi, Viet Nam. ${ }^{2}$ World Health Organization, WPRO, Manila, Philippines. ${ }^{3}$ Viet Nam Tobacco Control Fund, Viet Nam. ${ }^{4}$ Hanoi Medical University, Hanoi, Viet Nam. ${ }^{5}$ Hanoi University of Public Health, Hanoi, Viet Nam. ${ }^{6}$ Viet Nam General Statistics Office, Viet Nam.*For Correspondence: nguyentuanl@who.int 
(WHO) MPOWER package, the six effective measures to reduce tobacco use. It is also one of the most cost-effective interventions against NCDs, as recommended by WHO's Global Action Plan for the Prevention and Control of NCDs 2013-2020 (WHO, 2013).

Tobacco control has been identified as a public health priority in Viet Nam. In December 2004, the country ratified and became a party to the WHO Framework Convention on Tobacco Control (FCTC) and in 2012, enacted the national tobacco control law. The new law promulgates, among other tobacco control measures, the implementation of smoke-free environments covering indoor public places and workplaces.

In 2010, Viet Nam conducted the first Global Adult Tobacco Survey (GATS) and the survey was repeated in 2015. This provided a valuable opportunity to assess progress made in tobacco control, including the implementation of smoke-free environment in indoor workplaces. The GATS surveys utilized the standardized sampling design protocol developed by the Centre for Disease Control and Prevention (CDC) and WHO. A total of 9,925 interviews were completed for GATS 2010 and 8,996 for GATS 2015.

The purposes of this paper are 1) to examine the changes in the level of SHS exposure in workplaces in Viet Nam between 2010 and 2015,2) to examine associated factors for SHS exposure in indoor workplaces in 2015, and 3) to assess relative levels of contribution of those factors in the total reduction of the probability of SHS exposure between 2010 and 2015.

\section{Materials and Methods}

This paper utilized data from the Viet Nam GATS surveys 2010 from the WHO GATS database (WHO, 2016) and the GATS 2015 dataset from the Tobacco Control Fund-MOH Viet Nam. The Viet Nam GATS 2010 and 2015 are nationally representative surveys of adults aged 15 years and above and who identified Viet Nam as their primary place of residence. The two datasets were pooled and analysed using the Stata 14 software.

\section{Measurements}

The dependent variable of interest is the level of SHS exposure in indoor workplaces, which was defined as indoor workers who had noticed someone smoking in the indoor area where he or she had worked in the 30 days prior to the survey being conducted. Independent variables included: year of the survey, gender, smoking status, age-group, residence, education level, employment type, occupation, and workplace smoking policy.

Year of the survey was coded for 2010 and 2015. Gender included male and female and smoking status included current smokers and non-smokers. Age-group included 3 categories: (1) 15-24, (2) 25-44, and (3) 45 and above. Place of residence was categorized into rural and urban. Education was coded into 4 categories: (1) primary or less, (2) lower secondary, (3) upper secondary, (4) college or above. Employment type included: (1) informal sector worker, (2) non-government employee and (3) government employee. Occupation was coded into: (1) senior officials, (2) professional, (3) paraprofessional, (4) elementary, and (5) others. Workplace smoking policy was coded into: (1) not allowed anywhere indoors, (2) allowed in some indoor areas, (3) there is no policy, and (4) allowed everywhere. The latter refers to the internal smoke-free policies set by managers or owners of a workplace (which also reflect the level of the implementation of the national law in that workplace) as reported by survey participants. It should be noted that the occupation variable was asked differently in the 2010 and 2015 surveys, therefore, comparison of the level of SHS exposure using this variable was not possible.

Calculation were also made to estimate the number of workers protected from SHS exposure at the indoor workplaces by comparing the number exposed in 2015 with the number that would be exposed if the rate of SHS exposure were the same as in 2010.

\section{Statistical Analysis}

Descriptive and inferential statistical analyses were conducted using Stata 14 software. The survey design, including strata, cluster and weight, were declared in the software and used in all analysis in this paper. Two-year comparison of SHS was explored using descriptive analysis comparing levels of exposure overall and among sub-groups (i.e. the independent variables) between 2010 and 2015. Chi-square was used to test for statistical differences in the prevalence of SHS exposure between 2010 and 2015 GATS surveys.

The associated factors for SHS exposure in indoor workplaces were examined using univariate and multiple regressions. Poisson regression with robust variance estimators was used to estimate adjusted Prevalence Ratio (aPR) and their 95\% confidence intervals (CIs) for the cross-sectional data. This was achieved by treating the binary outcomes as count variables and assuming all the subjects had the same length of follow-up (Barros and Hirakata, 2003; Chen et al., 2016). Poisson regression was chosen because initial analysis showed that the proportion exposed to SHS in the indoors at work was high, which made it less appropriate to use OR as yielded by logistic regression (Barros and Hirakata, 2003; Deddens and Petersen, 2008; Chen et al., 2016). All the variable that showed significant $(\mathrm{p}<0.05)$ in the univariate model (Model 1) were included in the Poisson multiple regression model (Model 2). In the multiple regression model, the stepwise backward elimination procedure was applied until all variables in the model are significant $(\mathrm{P}<0.05)$. Beside the Poisson model, the same procedures were also done using logistic regression model (Model 3) and the results of the final multiple logistic regression model were also given for reference purpose only.

Each of the factors that showed significance in the multiple regression model were included in an additional regression models (model 2.a; 2.b; 2.c and 2.d) with the year of survey variable in order to assess the level of contribution of each of these variable in the reduction of SHS between 2015 and 2010, based on the change in the aPR of the variable Year of survey in these different models.

To help assess the fit of the regression model, the 
goodness-of-fit chi-squared test value was obtained. To help assess if there was any problem with over-dispersion of the data (i.e. when the conditional variance exceeds the conditional mean), negative binomial regression was used to obtain the chi-square value for the hypothesis that alpha equals zero.

\section{Results}

Comparison of SHS exposure in indoor workplaces between GATS 2010 and 2015

Between 2010 and 2015, there was a significant reduction in the overall level of SHS exposure at work from $55.9 \%$ in 2010 to $42.6 \%$ in 2015 (Table 1). This represents a $23.8 \%$ relative reduction between the two surveys $(\mathrm{p}<0.001)$. The reduction was almost evenly seen in all socioeconomic sub-groups between the two iterations of the survey. The highest reductions were observed in the groups who work in places where smoking indoors was not permitted from $24.6 \%$ in 2010 to $13.6 \%$ in
2015 (44.7\% relative reduction); and among government employees from $46.3 \%$ in 2010 to $30.1 \%$ in 2015 (35.0\% relative reduction). Among the non-smoking indoor workers alone, there was a highly significant reduction from $49.0 \%$ to $36.8 \%(\mathrm{P}<0.001)$ (i.e. a $24.9 \%$ relative reduction).

It is noted that on one hand, there was a large reduction in the level of SHS exposure in those workplaces where smoking is completely banned, on the other hand there was very little or no reduction in those workplaces where smoking is allowed everywhere, or smoking is allowed in some indoor areas or there is no policy.

Associated factors for SHS exposure in indoor workplaces

The association between socio-demographic factors and SHS exposure is presented in Table 2. The univariate regression model showed significance for all factors considered. However, after using stepwise backward elimination procedure in the multiple regressions model, only 4 out of the 8 factors were significant $(\mathrm{P}<0.05)$ and

Table 1. SHS exposure at indoor workplaces among Workers Aaged 15 Years and Above -a Comparison between 2010 and 2015, GATS, Viet Nam

\begin{tabular}{|c|c|c|c|c|c|}
\hline \multirow{4}{*}{$\begin{array}{l}\text { Demographic Characteristics } \\
\text { Overall }\end{array}$} & \multicolumn{5}{|c|}{ Exposure to SHS at workplaces } \\
\hline & \multirow{2}{*}{\multicolumn{2}{|c|}{$\begin{array}{c}2010 \\
\text { Percentage (95\% CI) }\end{array}$}} & \multirow{2}{*}{\multicolumn{2}{|c|}{$\begin{array}{c}2015 \\
\text { Percentage }(95 \% \mathrm{CI})\end{array}$}} & \multirow{3}{*}{$\begin{array}{c}\text { Relative Change (\%) } \\
-23.8^{* * *}\end{array}$} \\
\hline & & & & & \\
\hline & 55.9 & $(52.8,59.0)$ & 42.6 & $(39.9,45.3)$ & \\
\hline \multicolumn{6}{|l|}{ Gender } \\
\hline Male & 68.7 & $(64.9,72.2)$ & 54.4 & $(50.6,58.1)$ & $-20.8 * * *$ \\
\hline Female & 41.4 & $(37.2,45.7)$ & 29.9 & $(26.8,33.1)$ & $-27.8 * * *$ \\
\hline \multicolumn{6}{|l|}{ Smoking status } \\
\hline Non-smokers & 49.0 & $(45.4,52.6)$ & 36.8 & $(34.0,39.7)$ & $-24.9 * * *$ \\
\hline Smokers & 74.3 & $(69.8,78.5)$ & 63.3 & $(57.7,68.4)$ & $-14.8 * *$ \\
\hline \multicolumn{6}{|l|}{ Age (years) } \\
\hline $15-24$ & 49.2 & $(41.8,56.7)$ & 36.7 & $(30.5,43.4)$ & $-25.4 *$ \\
\hline $25-44$ & 58.0 & $(54.4,61.6)$ & 43.0 & $(39.7,46.4)$ & $-25.9 * * *$ \\
\hline 45 and above & 58.6 & $(53.6,63.5)$ & 48.4 & $(44.4,52.5)$ & $-17.4 * *$ \\
\hline \multicolumn{6}{|l|}{ Residence } \\
\hline Urban & 52.4 & $(49.1,55.7)$ & 39.8 & $(36.9,42.8)$ & $-24.0 * * *$ \\
\hline Rural & 59.0 & $(53.9,64.0)$ & 45.1 & $(40.7,49.5)$ & $-23.6 * * *$ \\
\hline \multicolumn{6}{|l|}{ Education Level } \\
\hline Primary or less & 66.1 & $(54.9,75.7)$ & 52.9 & $(41.9,63.6)$ & -20 \\
\hline Lower secondary & 61.1 & $(56.3,65.7)$ & 53.6 & $(49.0,58.2)$ & $-12.3 *$ \\
\hline Upper secondary & 61.6 & $(55.7,67.2)$ & 48.1 & $(41.7,54.6)$ & $-21.9 * *$ \\
\hline College or above & 45.6 & $(41.1,50.2)$ & 33.2 & $(29.5,37.0)$ & $-27.2 * * *$ \\
\hline \multicolumn{6}{|l|}{ Type of employment } \\
\hline Informal-sector worker & 68.4 & $(53.7,63.4)$ & 58.1 & $(53.6,62.5)$ & $-15.1 * * *$ \\
\hline Non-government employee & 33.4 & $(54.4,61.6)$ & 31.4 & $(27.3,35.9)$ & -6 \\
\hline Government employee & 46.3 & $(41.8,56.7)$ & 30.1 & $(26.0,34.5)$ & $-35.0 * * *$ \\
\hline \multicolumn{6}{|l|}{ Workplace smoking policy } \\
\hline Not allowed anywhere indoors & 24.6 & $(20.8,28.7)$ & 13.6 & $(11.3,16.4)$ & $-44.7 * * *$ \\
\hline Allowed in some indoor areas & 56.4 & $(50.3,62.3)$ & 51.7 & $(46.3,57.0)$ & -8.3 \\
\hline There is no policy & 82.1 & $(78.7,85.1)$ & 74.1 & $(69.1,78.6)$ & $-9.7 * *$ \\
\hline Allowed everywhere & 91.0 & $(86.1,94.3)$ & 90.1 & $(85.1,93.6)$ & -1 \\
\hline
\end{tabular}

$* \mathrm{p}<0.05, * * \mathrm{p}<0.01, * * * \mathrm{p}<0.001$ 
Table 2. Associated Factors for SHS Exposure at Indoor Workplaces, GATS 2010 and 2015, aged 15 Years and Older, Viet Nam

\begin{tabular}{|c|c|c|c|c|c|c|}
\hline $\begin{array}{l}\text { Demographic } \\
\text { Characteristics }\end{array}$ & \multicolumn{2}{|c|}{$\begin{array}{l}\text { Poisson univariate regression } \\
\text { aPR }(95 \% \text { CI) (Model 1) }\end{array}$} & \multicolumn{2}{|c|}{$\begin{array}{l}\text { Poisson multiple regression } \\
\text { aPR }(95 \% \mathrm{CI})(\text { Model } 2)\end{array}$} & \multicolumn{2}{|c|}{$\begin{array}{l}\text { Logistic multiple regression } \\
\text { OR }(95 \% \text { CI) (Model 3) }\end{array}$} \\
\hline \multicolumn{7}{|l|}{ Year of survey } \\
\hline 2010 & 1 & & 1 & & 1 & \\
\hline 2015 & $0.762 * * *$ & $(0.699,0.829)$ & $0.867 * * *$ & $(0.814,0.923)$ & $0.644 * * *$ & $(0.534,0.777)$ \\
\hline \multicolumn{7}{|l|}{ Gender } \\
\hline Male & 1 & & 1 & & 1 & \\
\hline Female & $0.572 * * *$ & $(0.527,0.621)$ & $0.706^{* * *}$ & $(0.657,0.757)$ & $0.390 * * *$ & $(0.326,0.465)$ \\
\hline \multicolumn{7}{|l|}{ Smoking status } \\
\hline Non-Smoker & 1 & & & & & \\
\hline Smokers & $1.64 * * *$ & $(1.53-1.76)$ & & & & \\
\hline \multicolumn{7}{|l|}{ Age (years) } \\
\hline $15-24$ & 1 & & & & & \\
\hline $25-44$ & $1.17 * *$ & $(1.03,1.33)$ & & & & \\
\hline 45-64 and above & $1.25^{* * *}$ & $(1.10,1.42)$ & & & & \\
\hline \multicolumn{7}{|l|}{ Residence } \\
\hline Urban & 1 & & & & & \\
\hline Rural & $1.13^{* *}$ & $(1.04,1.23)$ & & & & \\
\hline \multicolumn{7}{|l|}{ Education Level } \\
\hline Primary or less & 1 & & & & & \\
\hline Lower secondary & $0.891^{*}$ & $(0.803,0.988)$ & & & & \\
\hline Upper secondary & $0.883^{*}$ & $(0.787,0.990)$ & & & & \\
\hline College or above & $0.618^{* * *}$ & $(0.551,0.691)$ & & & & \\
\hline \multicolumn{7}{|l|}{ Type of employment } \\
\hline Informal sector worker & 1 & & 1 & & 1 & \\
\hline Non-government employee & $0.508^{* * *}$ & $(0.451,0.572)$ & $0.837 * * *$ & $(0.756,0.927)$ & $0.677 * *$ & $(0.532,0.861)$ \\
\hline Government employee & $0.578 * * *$ & $(0.522,0.640)$ & $1 . .02$ & $(0.921,1.12)$ & 0.963 & $(0.753,1.23)$ \\
\hline \multicolumn{7}{|l|}{ Workplace smoking policy } \\
\hline Not allowed anywhere indoors & 1 & & 1 & & 1 & \\
\hline Allowed in some indoor areas & $3.10 * * *$ & $(2.69,3.59)$ & $2.94 * * *$ & $(2.54,3.39)$ & $5.29 * * *$ & $(4.24,6.59)$ \\
\hline There is no policy & $4.49 * * *$ & $(3.93,5.14)$ & $3.98 * * *$ & $(3.43,4.62)$ & $14.2 * * *$ & $(10.9,18.4)$ \\
\hline Allowed everywhere & $5.21 * * *$ & $(4.56,5.95)$ & $4.61 * * *$ & $(3.98,5.34)$ & $39.4^{* * *}$ & $(26.1,59.3)$ \\
\hline
\end{tabular}

$\mathrm{p}<0.05, * * \mathrm{p}<0.01, * * * \mathrm{p}<0.001$

kept in the model. These includes: (1) year of survey, (2) gender, (3) type of employment and (4) workplace smoking policy.

An average workers in 2015 was less likely to be exposed to SHS compared to their counterpart in 2010 ( $\mathrm{aPR}=0.867 ; \mathrm{P}<0.001)$. Women were having lower risk of exposed to SHS at work than men $(\mathrm{aPR}=0.706 ; \mathrm{p}<0.001)$. Those who work in the non-government sector have lower risk of exposure to SHS compared with those who were self-employed workers $(\mathrm{aPR}=0.837 ; \mathrm{P}<0.001)$.

Most importantly, having a smoke-free policy in the workplace showed a significant and strong association with being protected from SHS exposure. Compared with workplaces with a complete smoking ban, those who worked in a workplace with a partial indoor smoking ban or with no policy are much more likely to be exposed to

Table 3. Changes in the aPR of the Year of Survey Variable, Reflecting the Level of Reduction of the Risk of Exposure to SHS between 2010 and 2015 of an Average Worker and Role of Different Factors

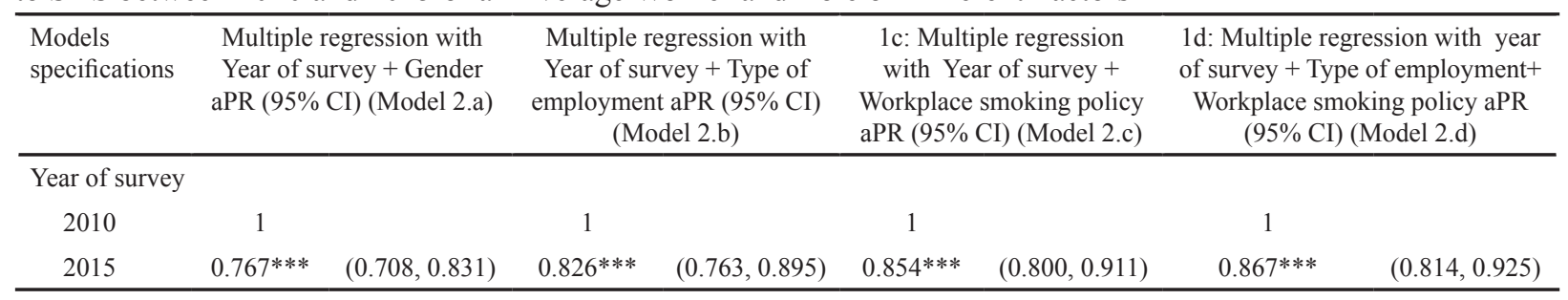


SHS $(\mathrm{aPR}=2.94$ and $\mathrm{aPR}=3.98$ respectively; $\mathrm{p}<0.001$ for both). Furthermore, the highest risk of SHS exposure was observed among those workers in an indoor workplace where smoking is allowed everywhere $(\mathrm{aPR}=4.61$; $\mathrm{p}<0.001$ ).

For other factors, including Smoking status, Age group, Residence and Education level there were significant difference of the aPR in the univariate regression model, but there is no significant difference found in the multiple regression model.

Both tests for the regression model showed that the model fits very well with the data and there is no problem with over-dispersion as the Hosmer-Lemeshow goodness-of-fit test gives $\mathrm{F}=0.81$ and $\mathrm{P}=0.60$, and the negative binomial regression gives the likelihood-ratio test of alpha $=0$ with $\mathrm{P}=1.00$.

On average a worker in 2015 has $23.8 \%$ reduction in the risk of exposure to SHS compared to his or her counterpart in 2010 (Table 2, Model 1: $\mathrm{aPR}=0.762$ ). Based on the further analysis to assess the contribution of each factor to the overall reduction of the risk of SHS exposure (Table 3 ), gender accounted for only about $0.5 \%$ reduction (Table 3, Model 2.a: aPR for year of survey increased from 0.762 in the univariate model to 0.767 in the model with Gender) in the risk of exposure to SHS at workplaces, type of employment account for about $6.4 \%$ reduction (Table 3, Model 2.b: aPR increased from 0.762 to 0.826 ,) while workplace smoking policy account for about $9.2 \%$ (Table 3, Model 2.c: aPR increased from 0.762 to 0.854 ).

When both variables "Type of employment" and "Workplace smoking policy" were added in the model (Table 3, Model 2d), the combined effect of the two variables is a reduction of only $10.5 \%$ (aPR for Year of survey increased from 0.762 to 0.867 ). That is, the combined effect of the two variables (as can be seen in the Model 2.b and Model 2.c) is less than the sum of the two (Model 2.d).

\section{Discussion}

In comparing the results of the Viet Nam GATS 2010 and 2015 surveys, there is evidence of a significant reduction (23.8\% relative reduction) in the level of SHS exposure at indoor workplaces, from $55.9 \%$ in 2010 to $42.6 \%$ in 2015 . As the results of the reduction in the rate of SHS exposure, there were 2.7 million more workers, including nearly 2 million nonsmokers, being protected from SHS exposure at indoor workplaces in 2015, as compared with 2010.

This reduction reflected the result of significant investment, effort, and progress made in tobacco control in the country in the period, especially the adoption of a strong tobacco control law in line with the WHO FCTC in 2012, and the establishment of the Viet Nam Tobacco Control Fund (VNTCF) in 2014 (WHO, 2016a), which has been providing sustainable funding for tobacco control activities in the country.

During 2014 and 2015, the VNTCF had invested $35 \%$ of the total of its income to support implementation of smoke-free settings in work and public places (WHO, 2016a). The effort included activities such as: disseminating the smoke-free provisions in the Law; conducting training on SHS harm and how to implement smoke-free workplace and public places for managers of public and workplaces; producing and disseminating no-smoking signs; and conducting mass media campaign on harm of SHS. As results, the percentage of respondents who reported working in an indoor workplace with a total indoor smoking ban increased significantly from 30.9\% in 2010 to $43.8 \%$ in 2015 ( $\mathrm{p}<0.001$ ) (author calculation).

Of the associated factors, being female proved to be a protective factor, having about $30 \%$ lower risk of explore to SHS compared to male counterpart. There seems to be some level of consideration for women by smokers at workplaces, e.g. smokers would try not to smoke when there were women in the room. This result is also consistent with studies in Germany (Fischer and Kraemer, 2016), and USA (Max et al., 2012). On the other hand, this factor does not seem to contribute any significant role in the reduction of SHS exposure between 2010 and 2015, with only about $0.5 \%$ of the reduction, as calculated from Table 3, Model 1. This could be explained by the fact that the composition of male and female worker stayed almost the same in the two surveys.

Regarding the type of employment, those working the informal sector has the highest risk of exposure to SHS exposure, while non-government workers have about $16.3 \%(\mathrm{aPR}=0.837)$ lower risk. This result is as expected, given the informal sector often has a lower level of compliance with the smoking ban in workplaces. Regarding the contribution in the overall reduction of the risk of SHS exposure between the two surveys, this factor contributed a sizable part, about $6.4 \%$ as calculated from the Table 3, Model 2.b. The main contribution seems to come from the fact that there is a smaller proportion of informal sector workers in 2015 (80.5\%-author calculation) as compared to that in $2010(88.4 \%$-author calculation).

The implementation and enforcement of smoke-free workplace policies proved to be the most important factor that affected levels of SHS exposure at indoor workplaces. The risk of SHS exposure was 4.6 times higher $(\mathrm{aPR}=4.61)$ in the workplaces where smoking is allowed everywhere compared with those places where smoking is completely banned. This result is similar to studies conducted in China, national level (Xiao et al., 2010), and 5 venues in Zhejiang Province (Xu et al., 2014), in which they found significant lower odds of exposure to SHS in the workplaces that had comprehensive smoking ban compared with the workplaces without the ban. This result shows that, even when there is a national smoke-free law in place, it is not effective if the law is not implemented by managers or owners of the workplace. Furthermore, this is also the factor that have accounted for the biggest impact in the reduction in the risk of exposure to SHS between 2015 and 2010, about $9.2 \%$, as calculated from the Table 3, Model 2.c.

The combined effects of the two variables "Type of employment" and "Workplace smoking policy" (Table 3, Model 2.d) were smaller than the sum of the impact of the two in the separate models (Model 2.b and Model 2.c) which suggested that the impact of reducing SHS 
exposure by the "Type of employment" between 2010 and 2015 had been partly achieved via the improvement of the workplace smoking policy in each of the type of employment categories.

It is noted that adding the Gender variable to the Model 2.b, Model 2.c and Model 2.d does not change the result of those models. There, the Gender variable was not included in those models.

Apart from the above three factors, the year of survey variable in the multiple regression model showed, as in Table 2, Model 2, that there are other factors that accounted for about $13.3 \%$ reduction $(\mathrm{aPR}=0.867)$ in the risk of exposure to SHS in the workplace in 2015 compared to 2010. Certainly, the communication efforts to raise awareness of smokers and their level of selfcompliance with the smoke-free indoor regulation played an important role in this part.

Although the level of SHS exposure in Viet Nam has decreased significantly between 2010 and 2015, it is still at a fairly high level compared with other countries where GATS surveys have been conducted. For example, in Turkey, SHS exposure at indoor workplaces was found to be the lowest at $15.6 \%$ in 2012, followed by Brazil at $24.4 \%$ in 2008 (WHO, 2016).

On the statistical side, the logistic regression results showed very high OR (up to 39.0) for selected indicators which can cause misleading interpretation of the level of association. This provided additional evidence to show that the use of Poisson regression is more suitable than logistic regression when the outcome is prevalent.

In summary, there was a statistically significant reduction in the level of SHS exposure at indoor workplaces and there was significantly higher percentage of respondents reporting working in a workplace with complete indoor smoking ban in 2015 compared to 2010 . This reflected the effort of the Ministry of Health and partners in the implementation of the tobacco control law, especially the implementation of smoke-free environment in public and workplaces during the period between 2010 and 2015. It was the internal workplace smoking policy of each workplace that played the most important role in deciding level of SHS exposure to workers.

The government should take special efforts to ensure all indoor workplaces issue and enforce their internal workplace smoking ban policy so as to effectively implement the smoke-free environment provision in the national law, to protect the health of their workers. This should include more communication campaigns target workplace owners and managers; trainings and regular inspections to ensure that the owners or managers of the workplaces issue and implement internal smoking ban policy covering all indoor areas in their workplaces.
This paper was made possible thanks to the available of the datasets provided by the Centers for Disease Control and Prevention in Atlanta (CDC), CDC Foundation, the World Health Organization and the Ministry of Health Viet Nam.

\section{Statement conflict of Interest}

None.

\section{References}

Barros AJ, Hirakata VN (2003). Alternatives for logistic regression in cross-sectional studies: an empirical comparison of models that directly estimate the prevalence ratio. $B M C$ Med Res Methodol, 3, 21.

Bauer JE, Hyland A, Li Q, et al (2005). A longitudinal assessment of the impact of smoke-free worksite policies on tobacco use. Am J Public Health, 95, 1024-9.

Chen JJ, Ho SY, Wang MP, et al (2016). Negative perceptions of parental smoking among 61810 Hong Kong adolescents: a cross sectional school based survey. Tob Prev Cessation, 2.

Deddens JA, Petersen MR (2008). Approaches for estimating prevalence ratios. Occup Environ Med, 65, 501-6.

Fischer F, Kraemer A (2016). Factors associated with secondhand smoke exposure in different settings: Results from the German Health Update (GEDA) 2012. BMC Public Health, 16, 327.

ILO (2005). Introductory Report: Decent Work - Safe Work [Online]. Available: http://www.ilo.org/wcmsp5/groups/ public/---europe/---ro-geneva/---sro-moscow/documents/ genericdocument/wcms_312093.pdf.

Max W, Sung H, Shi Y (2012). Exposure to Secondhand Smoke at Home and at Work in California. Public Health Rep, 127, 81-8.

MOH-Vietnam (2016). Global Adult Tobacco Survey (GATS) Viet Nam 2015 [Online].

WHO (2009). WHO Report on the Global Tobacco Epidemic, 2009: Implementing smoke-free environments [Online]. Available: http://www.who.int/tobacco/mpower/2009/en/.

WHO (2013). Global Action Plan for the Prevention and Control of NCDs 2013-2020 [Online]. Available: http://apps.who. int/iris/bitstream/10665/94384/1/9789241506236_eng. pdf?ua $=1$.

WHO (2016). Global Adult Tobacco Survey (GATS) online database [Online]. Available: http://www.who.int/tobacco/ surveillance/survey/gats/en/ [Accessed 29th January 2017].

WHO (2017). WHO Tobacco Free Initiative: Second-hand Tobacco Smoke [Online]. Available: http://www.who.int/ tobacco/research/secondhand_smoke/en/ [Accessed 25th March 2017 2017].

Xiao L, Yang Y, Li Q, et al (2010). Population-based survey of secondhand smoke exposure in China. Biomedial Environ Sci, 23, 430-6.

Xu Y, Wu Q, Xu S, et al (2014). Environmental secondhand smoke exposure and policy assessment at five venues in Zhejiang Province, China. Asia Pac J Public Health, 26, 622-30.

\section{Acknowledgments}

The authors want to cordially thank Prof Nguyen Thi Xuyen of the Viet Nam General Medical Association, WHO colleagues including Dr Katia De Pinho Campos, Ms Kathleen Lannan, Ms Ashlee Teakle and Ms Tuija Bercovici for their invaluable contribution and support for the writing of this paper.

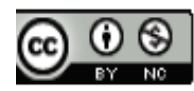

This work is licensed under a Creative Commons AttributionNon Commercial 4.0 International License. 